\title{
Bone remodeling in the context of cellular and systemic regulation: the role of osteocytes and the nervous system
}

\author{
Tadeusz Niedźwiedzki and Joanna Filipowska' \\ Department of Orthopedics and Physiotherapy, Collegium Medicum, Jagiellonian University, Cracow, Poland \\ ${ }^{1}$ Department of Cell Biology and Imaging, Institute of Zoology, Jagiellonian University, 9 Gronostajowa Street, \\ 30-387 Cracow, Poland
}

Correspondence

should be addressed

to J Filipowska

Email

joanna.filipowska@uj.edu.pl

\begin{abstract}
Bone is a dynamic tissue that undergoes constant remodeling. The appropriate course of this process determines development and regeneration of the skeleton. Tight molecular control of bone remodeling is vital for the maintenance of appropriate physiology and microarchitecture of the bone, providing homeostasis, also at the systemic level. The process of remodeling is regulated by a rich innervation of the skeleton, being the source of various growth factors, neurotransmitters, and hormones regulating function of the bone. Although the course of bone remodeling at the cellular level is mainly associated with the activity of osteoclasts and osteoblasts, recently also osteocytes have gained a growing interest as the principal regulators of bone turnover. Osteocytes play a significant role in the regulation of osteogenesis, releasing sclerostin (SOST), an inhibitor of bone formation. The process of bone turnover, especially osteogenesis, is also modulated by extra-skeletal molecules. Proliferation and differentiation of osteoblasts are promoted by the brainderived serotonin and hypothetically inhibited by its intestinal equivalent. The activity of SOST and serotonin is either directly or indirectly associated with the canonical Wnt/ $\beta$-catenin signaling pathway, the main regulatory pathway of osteoblasts function. The impairment of bone remodeling may lead to many skeletal diseases, such as high bone mass syndrome or osteoporosis. In this paper, we review the most recent data on the cellular and molecular mechanisms of bone remodeling control, with particular emphasis on the role of osteocytes and the nervous system in this process.
\end{abstract}

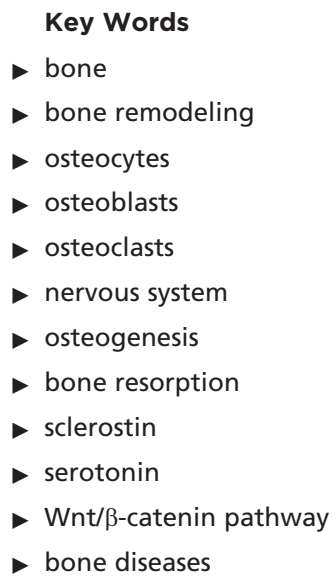

\section{Role of osteoclasts and osteoblasts in bone remodeling}

The bone is composed of extracellular matrix and bone cells at various stages of differentiation (Baron 2003, Pogoda et al. 2005). Moreover, it is filled with a network of blood vessels, nerve fibers, and bone marrow.
Maintenance of adequate bone mass, appropriate mechanical properties, and integrity of the skeleton requires constant bone remodeling. This process involves simultaneous resorption and formation of the bone,

Published by Bioscientifica Ltd 
contrary to bone modeling (formation), which is associated with an increase in bone mass and strength but excludes resorption (Boyce \& Xing 2008). This results in the repair of skeletal microinjuries on one hand and adaptation of the skeleton to constant mechanical load associated with everyday activities on the other. Bone growth (modeling) is the most intensive in the childhood and adolescence, before reaching full maturity. Uninterrupted osteogenesis in this period is a prerequisite for normal mechanical properties of the bones and their resistance to various pathologies, e.g., osteoporosis.

The phenomenon of bone turnover reflects activity of the two cellular populations: osteoclasts involved in the resorption of bone tissue and osteoblasts that form the new bone (Harada \& Rodan 2003, Teitelbaum \& Ross 2003). Bone remodeling takes place in the so-called basic multicellular unit, consisting of a group of osteoclasts forming the cutting cone in the front and a group of osteoblasts forming the closing cone behind. The latter associates with blood vessels and the peripheral innervation (Frost 1969, Elefteriou 2008; Fig. 1). Appropriate communication between bone cells and the cells of other organs is a prerequisite for maintaining homeostasis of the bone remodeling process. Recent studies of rare skeletal diseases identified a number of cellular and molecular mechanisms involved in the control of the bone remodeling process (Johnson 2015). We currently know that a shift toward excessive bone formation may result from a genetically determined disorder of sclerostin (SOST) synthesis in osteocytes, e.g., leading to van Buchem disease (van Lierop et al. 2013), or from mutation of the gene coding for LDL-receptor-related protein 5 (LRP5), a co-receptor involved in the Wnt/ $\beta$-catenin pathway. The latter pathway is particularly involved in bone formation, and thus its disruption leads to high bone mass disease (Boyden et al. 2002). Enhanced bone resorption, associated with the overactivity of osteoclasts, leads to osteoporosis, a frequent disease of older patients, especially postmenopausal women, characterized by increased bone fracture risk (Komoroski et al. 2014). However, a complete inhibition of bone resorption is equally unfavorable, as the overactivation thereof. Osteopetrosis is another consequence of osteoclast dysfunction (Albers-Schönberg 1904, Mellibovsky et al. 2004) mainly caused by the presence of mutations in the cells. The above-mentioned evidence points to a

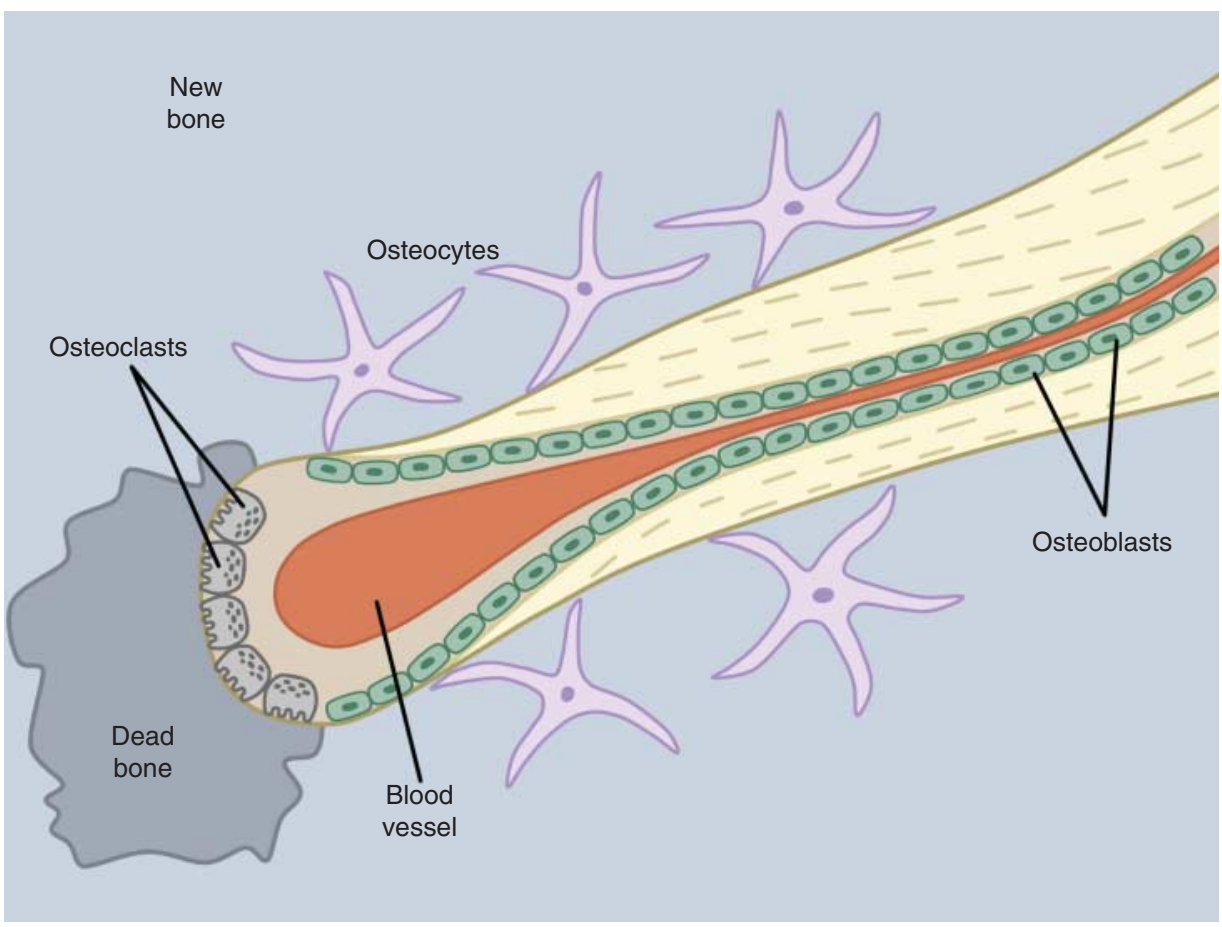

\section{Figure 1}

The process of cortical bone remodeling. The cutting cone, built of osteoclasts, moves forward and resorbs either a dead bone or a damaged/old bone matrix. The blood vessel delivers nutrients and growth factors for osteoblasts to lay down a new bone. Original artwork, based on microphotographs made by the authors and data from Parra-Torres et al. (2013). A full colour version of this figure is available at http://dx.doi.org/10.1530/JME-15-0067. 
significant role of physiological bone remodeling in the normal functioning of the skeleton and a whole body. Furthermore, the knowledge of cellular and molecular mechanisms involved at various stages of the bone remodeling process frequently constitutes the basis for pharmacotherapy of skeletal disorders. Identifying novel molecules and other intercellular mechanisms will give us a better understanding of how bone remodeling is controlled and should facilitate the development of new approaches to control bone remodeling and bone mass in a variety of pathological conditions.

The cells involved in bone remodeling, i.e., osteoclasts and osteoblasts (part of which finally differentiate into osteocytes at further stages of the process), originate from multipotent stem cells of the bone marrow (Del Fattore et al. 2010). The cells that give rise to osteoblasts and osteoclasts are mesenchymal stem cells (MSCs) and hematopoietic stem cells (HSCs) respectively (Del Fattore et al. 2010). These two cellular populations can be distinguished, e.g., on the basis of specific surface proteins expressed on their plasma membranes. MSCs are inter alia characterized by the surface expression of, e.g., CD73, CD90, and CD105 molecules, whereas HSCs express membrane receptors, such as CD34, CD45, and CD14 (Feisst et al. 2014). However, it is worth mentioning that Dominici et al. (2006) listed many other so-called minimal criteria, which besides surface markers characteristics, enable a more detailed definition of MSCs.

Osteoclasts are multinucleated cells, related to the cells of macrophage-monocyte and dendritic lineages (Ott 2004, Hirvonen et al. 2013). Osteoclasts are the first cells observed at the site of bone remodeling. Then, osteoblasts migrate to the area of resorption, fill it with a new bone matrix and control mineralization thereof (Ott 2004, Hirvonen et al. 2013; Fig. 1).

\section{Osteocytes and their central role in bone turnover}

While recent studies centered on the mechanisms of molecular communication between osteoblasts and osteoclasts during the regulation of bone metabolism (SanchezFernandez et al. 2008), the superior role of osteocytes entrapped inside small lacunae of a hard bone matrix in this process was mostly neglected. Despite being the largest fraction of bone cells ( $\sim 95 \%$ of all cells present in the adult skeleton), for long osteocytes were believed to be no more than differentiated osteoblasts, 'buried' in a bone matrix (Dallas et al. 2013) and long lived albeit incapable of proliferation and metabolically inactive (Neve et al. 2012,
Dallas et al. 2013). Therefore, most previous studies of osteocyte biology have focused around their morphology and topography within the lacunar-canalicular system, rather than around their function. Interestingly, osteocytes are not central cells exclusively for bone tissue. Owing to their involvement in systemic regulation of phosphate metabolism (Dallas et al. 2013), associated with the synthesis of fibroblast growth factor 23, they are postulated to be one of the most significant secretory cells of human body. A theory on the principal regulatory function of osteocytes on all stages of bone turnover process is still gaining a growing interest, and especially due to a significant clinical potential of osteocytes-derived SOST inhibition by specific antibodies (see 'The role of SOST in the regulation of bone growth and remodeling' below), these cells are now being extensively researched. Currently we know that osteocytes are the principal regulatory cells involved in the response of the bone to mechanical stimulation and control bone resorption and formation, modulating the function of osteoclasts and osteoblasts at a molecular level (Belanger et al. 1967, Kogianni \& Noble 2007). This control is particularly possible due to a secretion of SOST, an inhibitor of osteoblast activity, and other osteocyte cytokines, e.g., receptor-activator of NFк $\beta$ ligand (RANKL) or osteoprotegrin, a stimulator or an inhibitor of osteoclast differentiation respectively. A significant role of osteocytes as principal bone mechanosensitive cells rely on their capability to detect variations in the level of strain and distribute signals leading to adaptive responses. This is possible due to the formation of a functional osteocytes-abundant syncytium and strategic location of these cells within bone (Turner et al. 2002).

Mechanically stimulated osteocytes can communicate with each other via gap junctions, narrow channels extending between nearby cells. Gap junctions allow the communication between cells via the transfer of small molecules and ions. Recently, York et al. (2015) have shown that at supraphysiologic strains, the inhibition of gap junctional intercellular communication led to increases in SOST expression relative to cells in which communication was present. This study indicated that the gap-junctional communication may play a significant role in regulating bone remodeling. As already mentioned, SOST is one of the most crucial proteins involved in the control of bone remodeling by the osteocytes.

Some studies have shown that mechanical loading can promote bone formation, e.g., through downregulation of SOST expression in osteocytes. For example, $\mathrm{Tu}$ et al. (2012), using a mouse model in which the human SOST is expressed in osteocytes and is not

Published by Bioscientifica Ltd. 
regulated by loading, have demonstrated that a reduction of SOST is necessary for the stimulation of the expression of Wnt target genes and the increase in bone formation induced by mechanical force. However, Morse et al. (2014), through the experiments on the Sost ${ }^{-/-}$and WT mice have recently shown that the increase in bone formation under mechanical loading is unrelated to the SOST-dependent mechanism.

Recent studies showed that the activity of osteocytes during bone remodeling is under tight control of hormones secreted by other endocrine glands, such as the parathyroid hormone (PTH) of the parathyroid gland, a regulator of bone resorption and formation, or gonadal estrogen, an inhibitor of osteocyte apoptosis (Khosla et al. 2012, Rhee et al. 2013).

Osteocytes were shown to communicate with osteoblasts in a paracrine manner. The ability of osteocytes to modulate osteoblast function is associated with the synthesis of previously mentioned SOST (Neve et al.
2012, Dallas et al. 2013), an inhibitor of bone formation. As a result of this interaction, the rate of bone formation slows down (Fig. 2). Similar effects on bone formation can be observed in the presence of Dickkopf-1 (DKK1) protein (Li et al. 2011). The role of SOST in the physiology and pathology of the bone is discussed under 'The role of SOST in the regulation of bone growth and remodeling' below. Osteocytes can also affect the osteoblasts by a secretion of prostaglandin E2 (PGE2), nitric oxide (NO), and ATP, which stimulate the activity thereof (Fig. 2).

Li et al. (2012) exposed MLO-Y4 osteocyte-like cells to low-intensity pulsed ultrasound (LIPUS) stimulation in vitro and studied the effects of LIPUS-stimulated MLO-Y4-conditioned media (LIPUS-osteocyte-CM) on MC3T3-E1 preosteoblast proliferation and differentiation. MC3T3-E1 cells cultured in LIPUS-osteocyte-CM exhibited a significant inhibition of proliferation and an increased alkaline phosphatase (ALP) activity. LIPUS also enhanced secretion of PGE2 and NO in MLO-Y4. The authors thus

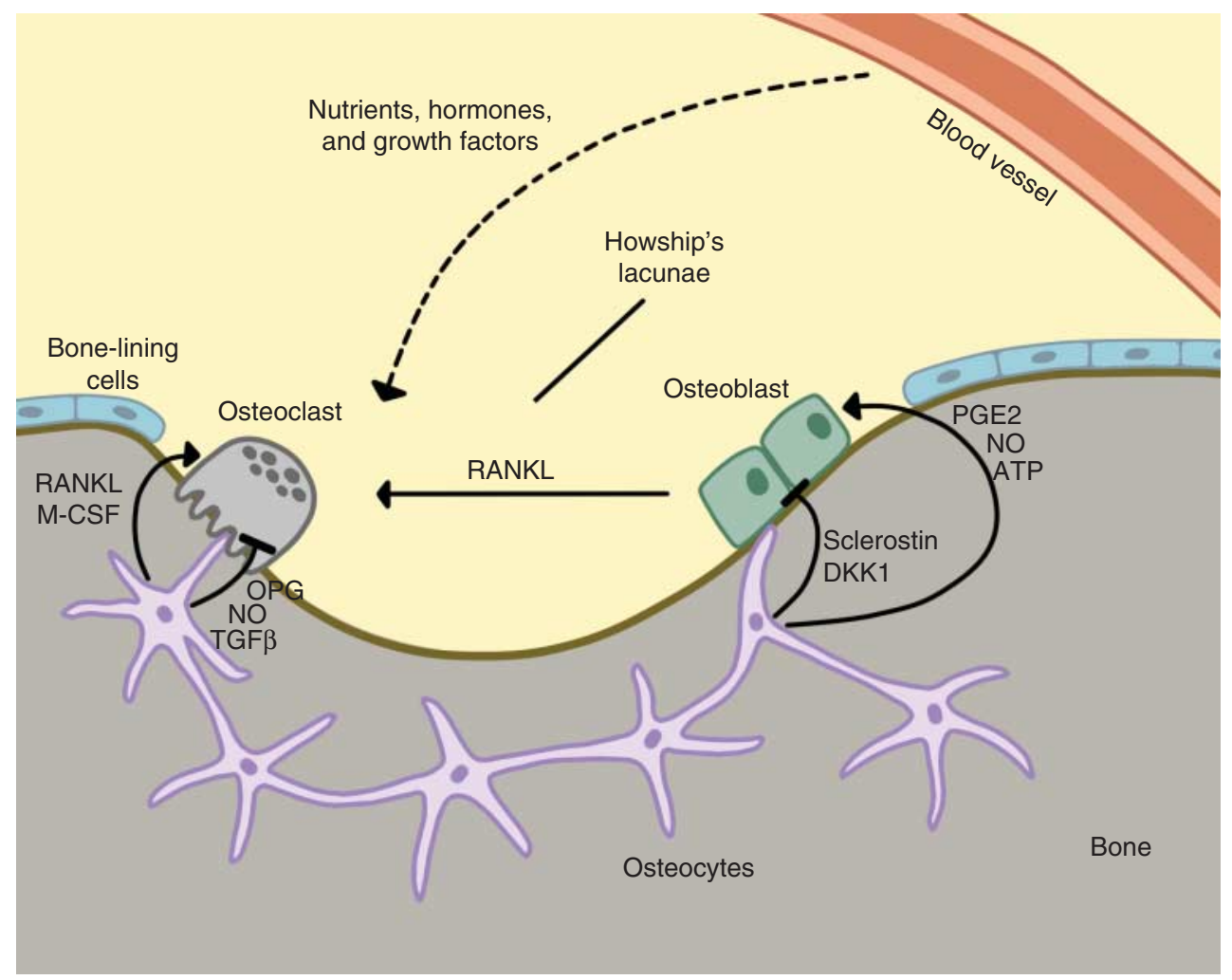

\section{Figure 2}

Interaction of bone cells: osteocytes, osteoblasts, and osteoclasts during the bone remodeling. Osteocytes activate osteoclasts via RANKL and M-CSF and inhibit their activity via OPG, NO, and TGF $\beta$. Osteocytes-derived PGE2, NO, and ATP stimulate, whereas sclerostin or DKK1 decrease osteoblasts activity. Osteoblasts interact with osteoclasts through RANKL. Bone-lining cells support the process of bone turnover. RANKL, receptor-activator of
$N F \kappa \beta$ ligand; M-CSF, macrophage colony stimulating factor; OPG, osteoprotegerin; NO, nitric oxide; TGF $\beta$, transforming growth factor beta; PGE2, prostaglandin E2; DKK1, Dickkopf-1. Original artwork, data from Kular et al. (2012), Zuo et al. (2012), and Parra-Torres et al. (2013). A full colour version of this figure is available at http://dx.doi.org/ 10.1530/JME-15-0067.

$$
\begin{aligned}
& \text { http://jme.endocrinology-journals.org } \\
& \text { DOI: 10.1530/JME-15-0067 }
\end{aligned}
$$


concluded that increased secretion of PGE2 by the osteocytes may play a role in a communication between LIPUS-stimulated MLO-Y4 and MC3T3-E1 cells.

Moreover, osteocytes modulate function of osteoclasts, either stimulating them to bone resorption or inhibiting their resorptive activity. Whereas some of the molecules synthesized by osteocytes, such as the macrophage colony stimulating factor and RANKL, promote osteoclast differentiation, the other, e.g., the proteins of the transforming growth factor beta (TGF $\beta$ ) superfamily and endothelial NO synthase, were shown to inhibit maturation of these cells (Pfeilschifter et al. 1988, Heino et al. 2002, Loveridge et al. 2002; Fig. 2).

Studies by Nakashima et al. (2011) and Xiong et al. (2011) demonstrated that osteocytes act as a major source of RANKL to promote osteoclastogenesis in adult bone remodeling. The knowledge on the bone cell interaction that is affected during the process of bone remodeling may help with the understanding of the bone pathophysiology at the tissue level and generate novel strategies targeting bone diseases. For example, it is currently well known how to inhibit RANKL (linking preosteoblasts and preosteoclasts) with denosumab (anti-RANKL antibody) (Leder et al. 2015) and SOST (linking osteocytes and osteoblasts) with, e.g., blosozumab to reduce bone resorption or increase bone formation (e.g., in osteoporosis) respectively (McColm et al. 2014) (see 'The role of SOST in the regulation of bone growth and remodeling' below).

Furthermore, recent findings point to an important role of osteocyte apoptosis in the regulation of bone turnover. Local skeletal microinjuries, e.g., related to bone fracture, induce osteocyte apoptosis; this stimulates osteoclasts and then osteoblasts to bone remodeling (Heino et al. 2009, Schaffler et al. 2014). Cardoso et al. (2009) showed for the first time that the blockade of osteocyte apoptosis completely inhibits the resorptive activity of osteoclasts. Activation of osteoclasts and osteoblasts may also result from the osteocyte necrosis caused by a mechanical stress and resultant inflammation (Heino et al. 2009, Schaffler et al. 2014). Torreggiani et al. (2013) showed that osteocytes not only regulate function of osteoblasts but also may dedifferentiate to the latter cells. This may happen whenever regeneration of an injury requires massive migration of osteoblasts and proliferation thereof. The ability of osteocytes to dedifferentiate was documented in a murine model, both in vitro and in vivo. According to Torreggiani et al. (2013), this phenomenon may be associated with exposure of osteocytes to external environment, e.g., during mechanical injury of the bone with disintegration of the surrounding tissues (due to bone fracture or surgical intervention, e.g., joint replacement or stabilization of fracture with metal screws). The external environment is an important source of various signals that may induce a transformation of osteocytes into proliferating osteoblasts, thus enabling healing of large bone defects. However, identification of the exact molecular mechanisms involved in the process of osteocyte dedifferentiation requires further research. Explanation of this phenomenon would undoubtedly have serious implications for novel strategies of regenerative medicine, based on an easy access to proliferating osteoblasts originating from terminally differentiated osteocytes. This is especially promising if the dedifferentiated cells could be obtained in an in vitro culture.

\section{Bone remodeling in the context of systemic regulation: role of nervous system}

Bone remodeling is a complex process modulated by a number of factors taking place simultaneously at many sites. Not only various substances released in an auto-, para- or endocrine manner control the activity of cells involved in the remodeling process; nowadays we know that also the CNS plays a vital role in this process acting, e.g., via an array of neurotransmitters and neuropeptides. Rich vascularization and innervation of the skeleton constitute the main source of various growth factors, neurotransmitters, and hormones regulating function of the bone also through the cooperation with other organs and tissues. Bone metabolism and remodeling are to a large extent controlled by, e.g., serotonin or a brainderived neurotrophic factor (Camerino et al. 2012, Masi 2012), a brain-derived neurotransmitter and growth factor, respectively. Synthesis of these factors is in turn under strong influence of hormones, e.g., leptin released from the adipose tissue (Masi 2012).

Bone is a richly innervated tissue. The topography of nerve fibers within the bone, especially those containing neuropeptides, is presently a subject of extensive research. Neuropeptides released from the bone nerve fibers were identified as enzymes, sensory, sympathetic, and glutaminergic peptides (Elefteriou 2005, Masi 2012). These neuropeptides play the roles of neurotransmitters and immunomodulators, acting in a paracrine manner, i.e., in the close vicinity of their source nerve endings (Ma et al. 2013). All bone cells express receptors for such neuropeptides as calcitonin gene-related protein (CGRP), substance P (SP), vasoactive intestinal peptide (VIP), and $N$-methyl-D-aspartate (Masi 2012). This constitutes an indirect proof for involvement of the CNS in the control of all of the biological processes, including those taking place

Published by Bioscientifica Ltd. 
in the bones, such as bone remodeling. The results published by Ma et al. (2013) suggest that neuropeptides, such as SP, CGRP, VIP, neuropeptide Y (NPY), or tyrosine hydroxylase, may stimulate proliferation of osteoblasts in vitro. Moreover, they were shown to promote the activity of ALP and synthesis of osteocalcin in osteoblasts, additionally facilitating communication between these cells via gap junctions. Mei et al. (2014) indicated that SP (at the range of concentration of $10^{-9}-10^{-8} \mathrm{M}$ ) added to in vitro cultures of the mouse MC3T3-E1 cell line significantly upregulated the expressions of osteoblastic genes: collagen type 1, ALP, osteocalcin, and Runx-2. Moreover, SP $\left(10^{-8} \mathrm{M}\right)$ promoted the transfer of $\beta$-catenin into the nucleus. The effects of SP treatment were inhibited by the neurokinin- 1 antagonist and DKK1, see "The role of Wnt/ $\beta$-catenin pathway in bone metabolism, and factors controlling this signaling pathway' below. These findings suggest that SP may enhance differentiation of MC3T3-E1 cells via regulation of the Wnt/ $\beta$-catenin signaling pathway. Also the work by Fu et al. (2014) indicated the osteoblastic differentiation and promotion of the angiogenic ability of rat bone marrow-derived MSCs under SP treatment via the Wnt signaling pathway.

Furthermore, the findings reported recently by Baldock et al. (2014) point to a significant role of NPY in the prevention of stress-induced bone loss. In their murine model-based study, these authors showed that NPY can directly regulate central and peripheral noradrenergic neurons, activating their receptors Y2, and thus preventing the release of noradrenaline. This mechanism likely protects us against the bone loss resulting from a stress-induced release of catecholamines.

The hypothalamus and brain stem are the structures of the CNS that likely play particularly important roles in the regulation of bone turnover (Driessler \& Baldock 2010). The hypothalamus and its semipermeable blood-brain barrier turned out to be one of the most potent intrinsic regulators that integrate not only the signals from peripheral tissues but also the internal signaling pathways of the brain.

\section{Cerebral and intestinal serotonin and its role in the bone turnover}

Pathways involving molecules synthesized outside the skeleton are equally important as the intrinsic SOST-based mechanisms of the bone growth control (see "The role of Wnt/ $\beta$-catenin pathway in bone metabolism, and factors controlling this signaling pathway' below). One of the most important extra-skeletal biologically active compounds regulating bone remodeling is serotonin (5-hydroxytryptamine); serotonin receptors are expressed on the plasma membranes of osteoblasts, osteoclasts, and osteocytes (de Vernejoul et al. 2012).

Mammalian serotonin is synthesized in the CNS and peripheral nervous system, whereby it acts as a neurotransmitter and hormone respectively (Goodrich et al. 1980, De-Miguel \& Trueta 2005, Kode et al. 2012). As serotonin does not penetrate across the blood-brain barrier, these two pools act independently from each other. Serotonin synthesized in the brain (corresponding to $5 \%$ of the entire serotonin pool) stimulates proliferation of osteoblasts indirectly, via hypothalamic neurons. Binding to the 5-hydroxytryptamine 2c (HTR2c) receptors on the plasma membrane of hypothalamic neurons, serotonin inhibits the transmission of sympathetic stimulation and inactivates type 2 beta adrenoreceptors present in osteoblast membranes (Fig. 3). In turn, the intestinal equivalent of cerebral serotonin, synthesized by the enterochromaffin cells and representing ca. 95\% of all body serotonin, inhibits the activity of osteoblasts, acting via the HTR1b; the latter receptor inactivates the protein kinase A signaling pathway that involves CREB transcription factor (Yadav et al. 2008, 2009; Fig. 3).

Serotonin is synthesized from tryptophan; its production in the CNS (brain stem) is catalyzed by tryptophan hydroxylase 2 (TPH2), and the intestinal synthesis by TPH1. As mentioned previously, there is a tight association between the activity of serotonin and leptin, a hormone of adipocytes, during the control of the bone remodeling process. Cerebral synthesis of serotonin is believed to be regulated by leptin, a hormone of adipocytes. Apart from the bone remodeling, leptin is also involved in a number of other processes, e.g., body weight control. Leptin prevents enhanced osteogenesis resulting from the overproduction of serotonin in the brain stem in a mechanism of negative feedback loop (D'Amelio et al. 2012). The role of leptin in the control of bone formation is indirectly associated with the activity of hypothalamic neurons. The inhibitory effect of leptin on the synthesis of serotonin is associated with the activation of leptin receptors on serotoninergic neurons of the brain stem. Another factor contributing to the inhibitory effect of leptin on the process of bone growth is a protein, neuromedin $\mathrm{U}$, a peptide synthesized by hypothalamic neurons and small intestinal cells, that plays an important role in the transmission of leptin signaling, acting downstream of leptin and inhibiting bone growth (Yadav et al. 2009, Driessler \& Baldock 2010). Impaired synthesis of leptin results in serious structural skeletal disorders, e.g., an increase in the mass of cancellous bone

Published by Bioscientifica Ltd. 


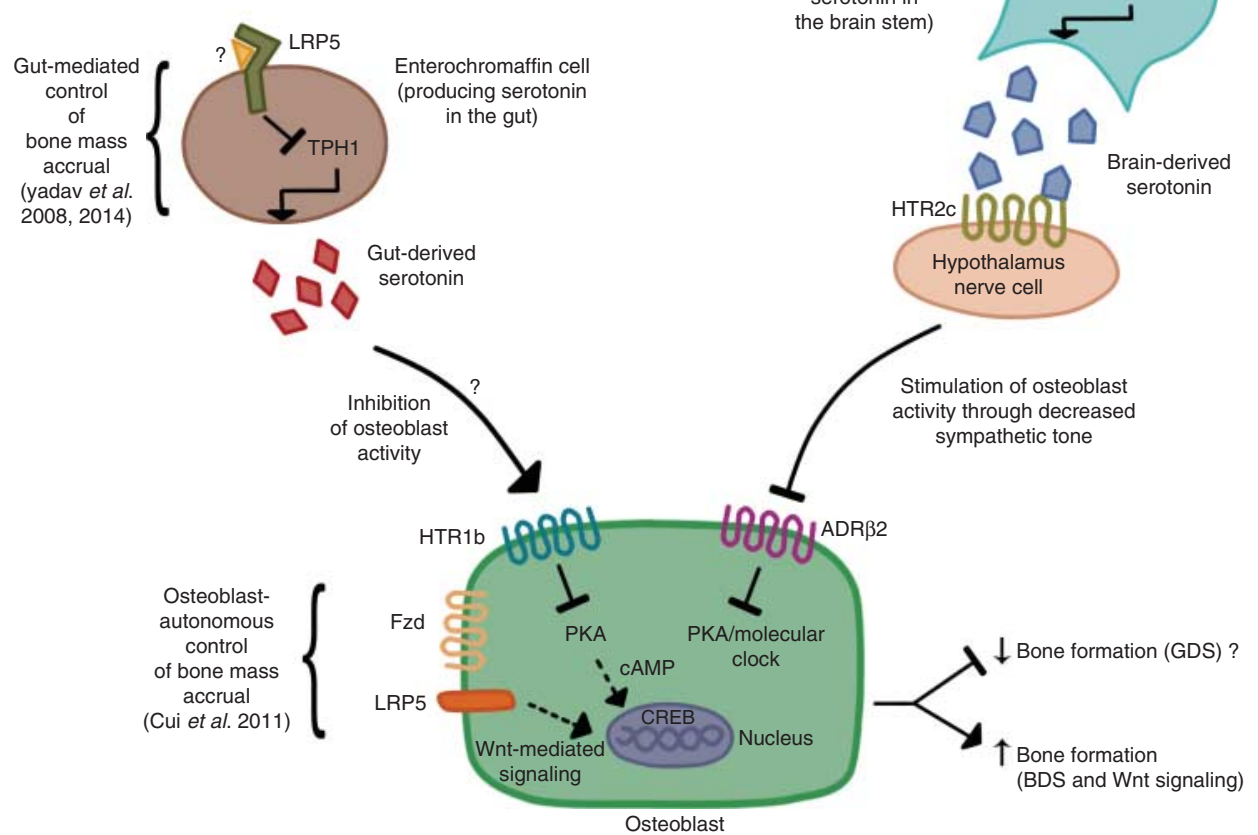

\section{Figure 3}

The mechanism of osteoblast activity regulation by brain- and gut-derived serotonin (BDS and GDS) respectively. GDS produced in the enterochromaffin cells by TPH1 enzyme inhibits osteoblast activity via the HTR1b, causing a reduced bone formation. Synthesis of GDS is decreased by LRP5 protein and its unknown ligand (Yadav et al. 2008, 2009). According to Cui et al. (2011), LRP5 acts in an autonomous-osteoblast manner to control Wnt-mediated signaling. BDS is synthesized in the brain stem neurons by the TPH2 enzyme. It stimulates osteoblast activity indirectly through the hypothalamus. BDS decreases sympathetic tone and activity of the ADR $\beta 2$

and simultaneous decrease in the total bone mass and length (D'Amelio et al. 2012). Moreover, leptin prevents excessive resorption of the bone, acting via a precursor protein of cocaine- and amphetamine-regulated transcript (CART) neuropeptide. Elefteriou et al. (2005) found that CART reduces the expression of RANKL, a key factor involved in osteoclast differentiation through nonadrenergic actions. Therefore, $\mathrm{Cart}^{-/-}$mice lose more bone than WT littermates in response to intracerebroventricular leptin (Elefteriou 2005, Driessler \& Baldock 2010).

A study of patients with depression treated with selective serotonin reuptake inhibitors showed that binding serotonin extracellularly (not only within a synaptic space but also in the gut) may exert a negative effect on bone mass (An et al. 2013). Data published by Gustafsson et al. (2006) point to the ability of osteoblasts and osteocytes to synthesize serotonin; this phenomenon receptor in an osteoblast plasma membrane. Production of BDS remains under control of leptin-adipocytes-derived hormones. Leptin indirectly inhibits BDS synthesis, causing a decreased osteoblast differentiation. TPH1 and TPH2, tryptophan hydroxylase 1 and 2; HTR1b/2c, 5-hydroxytryptamine (serotonin) receptor $1 \mathrm{~b} / 2 \mathrm{c}$; LRP5, LDL-receptor-related protein 5; ADR 32 , beta 2-adrenergic receptor; Fzd, Frizzled receptor. Original artwork, data from Ducy \& Karsenty (2010) and Cui et al. (2011). A full colour version of this figure is available at http://dx.doi.org/10.1530/JME-15-0067.

was confirmed in an in vitro study of human and murine cells, analyzing the mRNA level for the Tph1-encoding gene transcript. This may point to another potential cellular regulatory mechanism of bone growth. As mentioned previously, contrary to its cerebral equivalent, the serotonin of intestinal origin inhibits bone formation. Recent studies documented tight association between the activity of intestinal enterochromaffin cells and osteoblasts in the regulation of bone growth; however, the exact nature of this interaction is still not completely understood and there are many unsolved controversies around this issue. According to one theory, osteoblasts may inhibit the synthesis of intestinal serotonin acting via the LRP5 protein present in the plasma membrane of the enterochromaffin cells (Fig. 3); this neutralizes the inhibitory effect of serotonin on bone growth and thus enables osteogenesis (Yadav et al. 2008). Deletion of the

Published by Bioscientifica Ltd. 
LRP5-encoding gene in enterochromaffin cells was reflected by the overexpression of $T p h 1$, release of intestinal serotonin into circulation and inhibition of bone growth (Yadav et al. 2008). The postulated ability of osteoblasts to affect the synthesis of serotonin points to a significant cellular mechanism of bone growth control. However, Cui et al. (2011) obtained contradictory results, indicating that peripheral (i.e., gut-derived serotonin) does not affect bones and the role of LRP5 in the intestine is not related to Tph1 inhibition (Fig. 3). These authors rather suggest that osteoblasts activity is under control of LRP5, present in their plasma membrane, which is directly associated with the Wnt signaling pathway. It is the so-called autonomous-osteoblast control of the bone mass accrual. Thus, according to Cui et al. (2011), the mutations in osteoblasts, but not enterochromaffin cells-derived LRP5, lead to different impaired skeletal phenotypes, e.g., high bone mass or osteoporosis-pseudoglioma syndrome. Serotonin may also regulate the activity of osteoclasts. Chabbi-Achengli et al. (2012) revealed that serotonin is vital not only for osteoblasts but also for osteoclast differentiation and showed that the synthesis of serotonin by these cells may be additionally enhanced by RANKL, generated by osteoblasts. All of this evidence points to the crucial role of serotonin in the regulation of both bone formation and bone resorption.

\section{The role of $\mathrm{Wnt} / \beta$-catenin pathway in bone metabolism, and factors controlling this signaling pathway}

The Wnt glycoproteins are involved in the control of many developmental processes, including the formation of mesoderm and organogenesis (Logan \& Nusse 2004). The results of recent studies suggest that these proteins may also play a role in the development of some neoplasms (Sharma et al. 2014, Zhang et al. 2014). A total of 19 members of the Wnt family were described to date. Wnt-mediated signaling controls renewal and proliferation of stem cells and stimulates differentiation of osteoprogenitor cells (Baron \& Kneissel 2013, Clevers 2013). In particular, Wnt7b and Wnt10b are postulated to play the significant important roles in the process of bone mass control (Kubota et al. 2010). Mice with mutations of the Wnt7b and Wnt10b genes presented with impaired osteogenesis and slower bone growth rate respectively (Bennett et al. 2007, Tu et al. 2007). However, it also is worth mentioning two other members of the Wnt superfamily, namely Wnt1 and Wnt16, which have recently been revealed to play an important role in either the bone formation or repression of osteoclastogenesis and the prevention of cortical bone fragility fractures respectively (Laine et al. 2013, Moverare-Skrtic et al. 2014).

The Wnt proteins can activate at least three independent signaling pathways that are crucial for bone remodeling. The most important of them is the so-called canonical Wnt pathway, involving a cytoplasmic protein, $\beta$-catenin. Another pathway, the so-called non-canonical Wnt pathway, involves two distinct mechanisms: planar cell polarity (important during embryogenesis) and the regulation of calcium ion concentration within the bone cells (Wang et al. 2014).

The canonical Wnt pathway (Fig. 4) may be interrupted due to the blockade of the Wnt signaling for the Frizzled (Fzd) receptors expressed on the osteoblast surface. This blockade, for example, associated with the activity of SOST, leads to degradation of $\beta$-catenin, resulting from phosphorylation of this protein. The latter reaction is catalyzed by glycogen synthase kinase 3 beta (GSK3 $\beta$ ), acting in complex with other proteins, e.g., adenomatous polyposis coli (APC) or axin. If the Wnt signal reaches osteoblasts, their Fzd receptors bind to their co-receptors, LRP5 or LRP6, and deactivate the GSK3 $\beta$ complex; this enables the passing of the $\beta$-catenin signal to the cell nucleus and activation of genes that control the proliferation and differentiation of osteoblasts via T-cell factor/lymphoid-enhancer factor transcription factors (Kubota et al. 2010). Wnt signaling is currently emerging as an essential pathway targeted in bone regeneration (Leucht \& Helms 2015). Minear et al. (2010) have shown that another member of the Wnt family (Wnt3a) stimulates the proliferation of skeletal progenitor cells and accelerates their differentiation into osteoblasts, when packaged into liposomal vesicles and delivered into mouse skeletal defects. The liposome-based delivery of Wnt3a enhances its activity and results in faster bone regeneration, i.e., increased mineralization and osteoid formation, when compared to the control (liposome-entrapped PBS; Minear et al. 2010). These data suggest that Wnt signaling can be amplified successfully at the injury site, being an alternative for bone morphogenetic proteins (BMPs)-based bone therapies. Recently, Leucht et al. (2013) also demonstrated that liposomal Wnt3a enhances cell survival and reestablishes the osteogenic capacity of bone grafts from aged rabbits. This may indicate a new strategy of bone therapy, e.g., in individuals suffering from diminished bone healing potential.

Apart from other genes, the Wnt signaling pathway controls the expressions of $R U N X-2$ and C-MYC, i.e., the

Published by Bioscientifica Ltd 


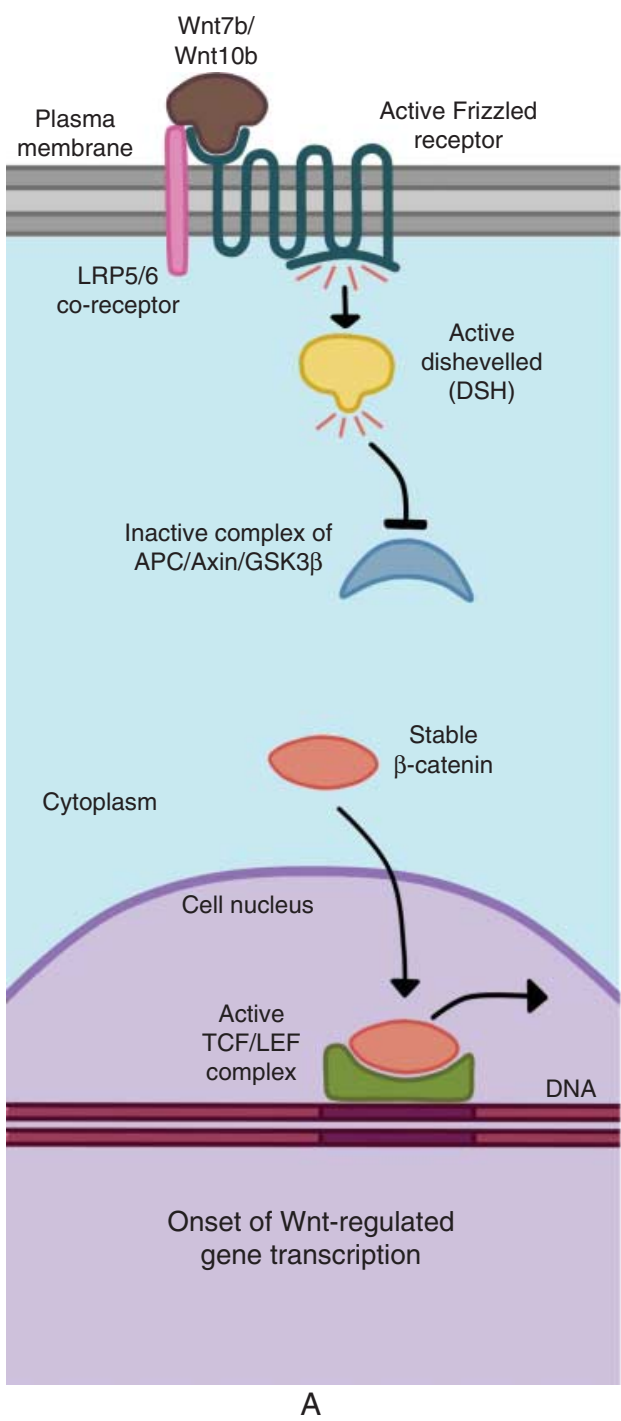

A

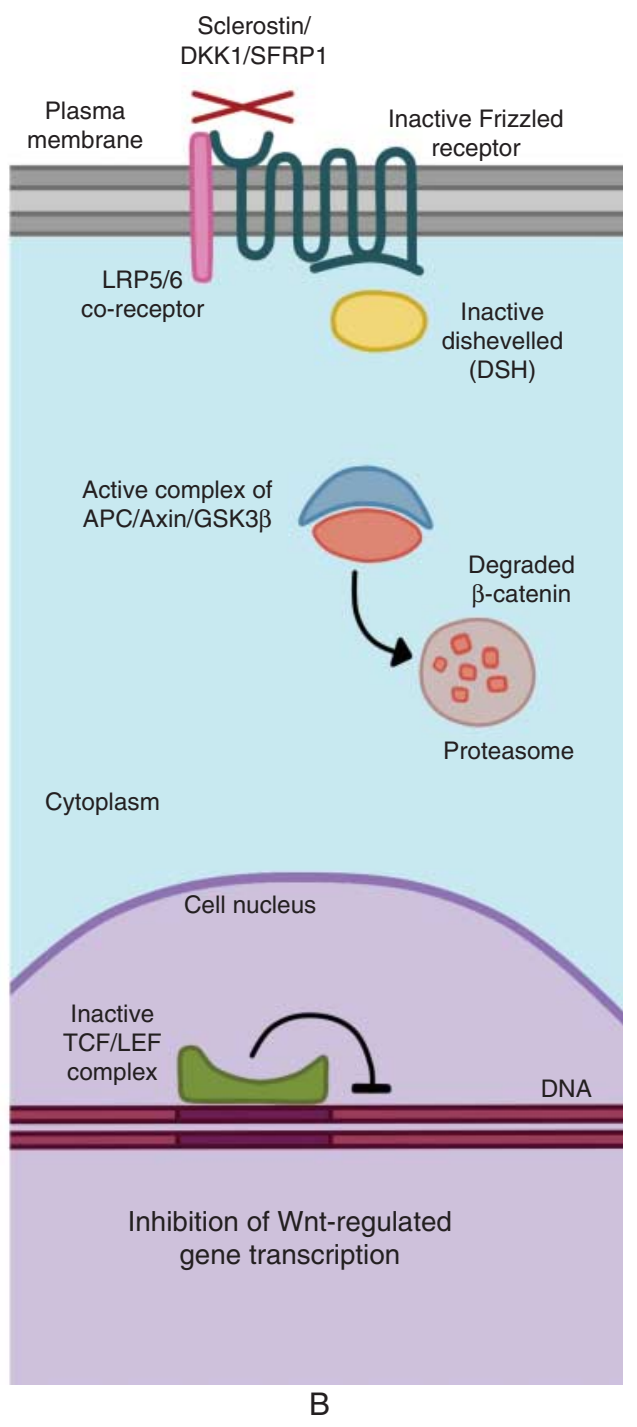

by APC/Axin/GSK3 $\beta$ and its further proteosomal degradation. Degraded $\beta$-catenin is unable to activate a Wnt-dependent gene transcription in the nucleus of osteoblast. Fzd, Frizzled receptor; Dsh, dishevelled; APC/Axin/GSK3 $\beta$, the complex of adenomatous polyposis coli (APC), axin, and glycogen synthase kinase 3 beta (GSK3 $\beta$ ); sFRP1, soluble Frizzled-related protein 1; DKK1, Dickkopf-1; LRP5 or LRP6, LDL-receptor-related protein 5 or 6; TCF, T-cell factor; LEF, lymphoid-enhancer factor. Original artwork, data from Bennett et al. (2007). A full colour version of this figure is available at http://dx.doi.org/10.1530/JME-15-0067.

cultures (Almeida et al. 2011, Thiele et al. 2012). Because Wnt signaling is essential for a proper differentiation of osteoblasts as mentioned previously, glucocorticoids can decrease bone formation, leading to osteoporosis. Thus, inhibition of SOST, DKK1, or sFRP1 may potentially constitute a therapeutic target in patients with glucocorticoid-induced osteoporosis (Gifre et al. 2013, Guanabens et al. 2014).

Published by Bioscientifica Ltd. http://jme.endocrinology-journals.org DOI: 10.1530/JME-15-0067
(C) 2015 Society for Endocrinology Printed in Great Britain 


\section{The role of SOST in the regulation of bone growth and remodeling}

Several physiological mechanisms prevent both insufficient and excessive bone formation, equally unfavorable as the excessive (e.g., osteoporosis-associated) resorption. One of them is paracrine signaling, i.e., communication between osteocytes and osteoblasts. Recent studies unambiguously confirmed that the process of bone formation (i.e., proliferation and differentiation of osteoblasts) is modulated by SOST, an osteocyte-synthesized protein (Neve et al. 2012, Dallas et al. 2013). SOST is encoded by the sclerosis-bone dysplasia, sclerosteosis (SOST) gene, located on the long (q) arm of chromosome 17 at position 11.2. Owing to the presence of a cysteine knotlike domain in its secondary structure, SOST is classified as the differential-screeningselected gene aberrant in neuroblastoma glycoprotein (Balemans et al. 2001, Brunkow et al. 2001, van Bezooijen et al. 2005). Although the expression of mRNA for the SOST transcript is observed during embryogenesis of many tissues (McNulty et al. 2012), the product of this gene, SOST, is biosynthesized solely during the postnatal period and is specific for differentiated cells: osteocytes, hypertrophic mineralized chondrocytes and cementocytes (Winkler et al. 2003, van Bezooijen et al. 2004, 2009, Poole et al. 2005) and articular chondrocytes (Chan et al. 2011, Roudier etal.2013). SOST is a down regulator of bone formation. However, besides inhibiting bone formation, it can also induce osteoclast formation (Wijenayaka et al. 2011). Binding to co-receptors of the LRP family, LRP5 or LRP6, SOST acts as an antagonist of Wnt/ $\beta$-catenin signaling pathway (Fig. 4; Li et al. 2005) and thus inhibits survival, proliferation, and differentiation of osteoblasts and promotes survival of osteocytes. Both in vitro and in vivo studies showed that the intracellular Wnt/ $\beta$-catenin signaling pathway can be activated due to mechanical stimulation of bone cells (Hens et al. 2005, Robinson et al. 2006, Lin et al. 2009). Very recently, Lara-Castillo et al. (2015) have postulated that mechanical load initially activates $\beta$-catenin signaling in osteocytes via a PG and Akt-mediated mechanism. According to these authors, initial activation of $\beta$-catenin signaling in the subset of osteocytes activates a subsequent propagation of the 'load signal' to the adjacent osteocytes, which further reaches the cells on the bone surfaces. This signal propagation and activation of $\beta$-catenin signaling in the osteocytes is connected to the decreased expression of the LRP5/ 6 and Wnt ligand inhibitors, e.g., SOST and DKK1. As mentioned previously, the inhibitory effect of SOST on bone formation is potentiated by glucocorticoids (Gifre et al. 2013) and can be counterbalanced by PTH, administered in the form of teriparatide (PTH 1-34); this evidence constitutes the basis of currently tested experimental therapeutic approaches, e.g., treatment of glucocorticoids-induced osteoporosis (Lau \& Adachi 2010). Apart from NO, synthesis of SOST is also inhibited by PGs, especially PGE2 (Genetos et al. 2011). Furthermore, Papanicolaou et al. (2009) demonstrated the effects of BMPs on SOST expression at the mRNA/protein levels in different bone cell lines of the mouse origin (MLO-Y4, MLO-A5, and UMR 106.01). The authors have shown that in mature MLO-Y4 osteocytes, treatment with BMP2, BMP4, or BMP6 was without effect on Sost but induced a robust increase in Sost expression in immature MLO-A5 osteocytes. Oscillatory fluid flow applied to mature UMR 106.01 osteoblasts transiently decreased expression of SOST at both the mRNA and protein levels. The results obtained by Papanicolaou et al. (2009) indicate that BMP treatment and in vitro mechanical loading demonstrate opposite effects on SOST expression.

Five mutations of the SOST gene were described to date, including three associated with a the premature termination of translation and another two resulting in impaired splicing of the SOST transcript during posttranscriptional processing. Furthermore, impaired bone formation may result from the deletion of the DNA segment regulating the expression of the SOST gene (Loots et al. 2005). As a result of this mutation, SOST no longer exerts its inhibitory effect on bone formation, which leads to hyperplasia, a typical manifestation of sclerosteosis and van Buchem disease (Balemans et al. 2001, 2005, Brunkow et al. 2001, Loots et al. 2005, Kim et al. 2008). Understanding the molecular background of these two conditions provided novel therapeutic options for patients with excessive bone formation and individuals with osteoporosis (McClung et al. 2014). One example of such novel therapy is a MAB that selectively binds SOST (trade name: romosozumab); the results of ongoing clinical trials (currently phase 3 ) point to high efficacy of this agent in the management of osteoporosis (van Dinther et al. 2013, Pinkerton et al. 2013). This raises hopes for successful treatment of this condition frequently diagnosed in postmenopausal women. Excessive production of SOST may also potentially be inhibited with blosozumab, a specific monoclonal anti-SOST antibody already tested in a phase 1 clinical trial on healthy, postmenopausal women (McColm et al. 2014).

\section{Conclusion}

The skeleton is not a static structure. Throughout the lifetime, it undergoes a continuous remodeling, i.e., a

Published by Bioscientifica Ltd. 
dynamic reorganization of the bone. This phenomenon is observed either under physiological conditions, as an effect of dynamic forces generated during usual everyday activities or during regeneration of the bone after trauma. Bone remodeling occurs in response to various factors, e.g., hormones, cytokines, chemokines and biomechanical, external stimuli, and is vital not only for the maintenance of a normal bone mass and strength but also for mineral homeostasis. Bone remodeling is specifically regulated by a crosstalk between bone cells. The process of bone remodeling involves resorption, controlled by osteoclasts, and bone formation, associated with the activity of osteoblasts. However, osteocytes located within the mineralized bone matrix seem to play a superior role in the regulation of bone remodeling at a cellular and molecular level. Recently osteocytes, previously considered metabolically inactive cells, have raised interest as key regulatory components of the bone and one of the most important endocrine cells of the body. Impaired synthesis and secretion of various osteocyte-derived molecules, especially SOST, may lead to many skeletal pathologies, resulting from either too low (e.g., in van Buchem disease) or too high (e.g., in postmenopausal osteoporosis) synthesis of this protein, which may promote excessive or cause decreased bone formation (and thus regeneration) respectively (Zhou et al. 2013). Bone is a richly innervated and vascularized tissue. Therefore, the CNS with its neurotransmitters and neuropeptides, growth factors, and hormones along with other systems play vital roles in the process of bone turnover.

Apart from skeletal innervation, the need for a tight control of bone remodeling is also reflected by the activity of extra-skeletal regulators of the process, e.g., cerebral and hypothetically intestinal serotonin. As a source of serotonin, the brain stem plays a pivotal role in the control of new bone formation.

Constant remodeling and adaptation of bone tissue to mechanical loads is not the only principal role of the skeletal system. Bones are increasingly referred to as the central hormonal organs of the human body, not only regulating metabolism of the skeletal system but also strongly affecting the function of other organs and tissues. This is of vital importance as many pathologies of the skeleton may give rise to systemic disorders. Therefore, further identification of other molecular mechanisms related to bone remodeling and metabolism will not only provide better insight into these processes but also define novel strategies for the treatment of skeletal as well as systemic diseases.
Declaration of interest

The authors declare that there is no conflict of interest that could be perceived as prejudicing the impartiality of this review.

\section{Funding}

This review did not receive any specific grant from any funding agency in the public, commercial or not-for-profit sector.

\section{References}

Albers-Schönberg H 1904 Röntgenbilder einer seltenen Knochenerkrankung. Münchener Medizinische Wochenschrift 51 365-368.

Almeida M, Han L, Ambrogini E, Weinstein RS \& Manolagas SC 2011 Glucocorticoids and tumor necrosis factor $\alpha$ increase oxidative stress and suppress Wnt protein signaling in osteoblasts. Journal of Biological Chemistry 286 44326-44335. (doi:10.1074/jbc. M111.283481)

An KY, Shin WJ \& Lee KJ 2013 The necessity of bone densitometry for patients taking selective serotonin reuptake inhibitors. Journal of Bone Metabolism 20 95-98. (doi:10.11005/jbm.2013.20.2.95)

Baldock P, Lin S, Zhang L, Karl T, Shi Y, Driessler F, Zengin A, Hormer B, Lee N, Wong I et al. 2014 Neuropeptide Y attenuates stress-induced bone loss through suppression of noradrenaline circuits. Journal of Bone and Mineral Research 29 2238-2249. (doi:10.1002/jbmr.2205)

Balemans W, Ebeling M, Patel N, Van Hul E, Olson P, Dioszegi M, Lacza C, Wuyts W, Van Den Ende J, Willems P et al. 2001 Increased bone density in sclerosteosis is due to the deficiency of a novel secreted protein (SOST). Human Molecular Genetics 10 537-543. (doi:10.1093/ hmg/10.5.537)

Balemans W, Cleiren E, Siebers U, Horst J \& Van Hul W 2005 A generalized skeletal hyperostosis in two siblings caused by a novel mutation in the SOST gene. Bone 36 943-947. (doi:10.1016/j.bone.2005.02.019)

Baron R 2003 Anatomy and ultrastructure of bone. In Primer on the Metabolic Bone Diseases and Disorders of Mineral Metabolism, 5th edn, pp 1-8.

Baron R \& Kneissel M 2013 WNT signaling in bone homeostasis and disease: from human mutations to treatments. Nature Medicine 19 179-192. (doi:10.1038/nm.3074)

Belanger LF, Choquette LP \& Cousineau JG 1967 Osteolysis in reindeer antlers; sexual and seasonal variations. Calcified Tissue Research 137-43. (doi:10.1007/BF02008073)

Bennett CN, Ouyang H, Ma YL, Zeng Q, Gerin I, Sousa KM, Lane TF, Krishnan V, Hankenson KD \& MacDougald OA 2007 Wnt10b increases postnatal bone formation by enhancing osteoblast differentiation. Journal of Bone and Mineral Research 22 1924-1932. (doi:10.1359/ jbmr.070810)

van Bezooijen RL, Roelen BA, Visser A, van der Wee-Pals L, de Wilt E, Karperien M, Hamersma H, Papapoulos SE, ten Dijke P \& Lowik CW 2004 Sclerostin is an osteocyte-expressed negative regulator of bone formation, but not a classical BMP antagonist. Journal of Experimental Medicine 199 805-814. (doi:10.1084/jem.20031454)

van Bezooijen RL, Papapoulos SE \& Lowik CW 2005 Bone morphogenetic proteins and their antagonists: the sclerostin paradigm. Journal of Endocrinological Investigation 28 15-17. (doi:10.1007/BF03347215)

van Bezooijen RL, Bronckers AL, Gortzak RA, Hogendoorn PC, van der Wee-Pals L, Balemans W, Oostenbroek HJ, Van Hul W, Hamersma H, Dikkers FG et al. 2009 Sclerostin in mineralized matrices and van Buchem disease. Journal of Dental Research 88 569-574. (doi:10.1177/ 0022034509338340)

Boyce BF \& Xing L 2008 Functions of RANKL/RANK/OPG in bone modeling and remodeling. Archives of Biochemistry and Biophysics 473 139-146. (doi:10.1016/j.abb.2008.03.018)

Published by Bioscientifica Ltd. 
Boyden LM, Mao J, Belsky J, Mitzner L, Farhi A, Mitnick MA, Wu D, Insogna $\mathrm{K} \&$ Lifton RP 2002 High bone density due to a mutation in LDL-receptor-related protein 5. New England Journal of Medicine 346 1513-1521. (doi:10.1056/NEJMoa013444)

Brunkow ME, Gardner JC, Van Ness J, Paeper BW, Kovacevich BR, Proll S, Skonier JE, Zhao L, Sabo PJ, Fu Y et al. 2001 Bone dysplasia sclerosteosis results from loss of the SOST gene product, a novel cystine knotcontaining protein. American Journal of Human Genetics 68 577-589. (doi:10.1086/318811)

Camerino C, Zayzafoon M, Rymaszewski M, Heiny J, Rios M \& Hauschka PV 2012 Central depletion of brain-derived neurotrophic factor in mice results in high bone mass and metabolic phenotype. Endocrinology 153 5394-5405. (doi:10.1210/en.2012-1378)

Cardoso L, Herman BC, Verborgt O, Laudier D, Majeska RJ \& Schaffler MB 2009 Osteocyte apoptosis controls activation of intracortical resorption in response to bone fatigue. Journal of Bone and Mineral Research 24 597-605. (doi:10.1359/jbmr.081210)

Chabbi-Achengli Y, Coudert AE, Callebert J, Geoffroy V, Cote F, Collet C \& de Vernejoul MC 2012 Decreased osteoclastogenesis in serotonindeficient mice. PNAS 109 2567-2572. (doi:10.1073/pnas.1117792109)

Chan BY, Fuller ES, Russell AK, Smith SM, Smith MM, Jackson MT, Cake MA, Read RA, Bateman JF, Sambrook PN et al. 2011 Increased chondrocyte sclerostin may protect against cartilage degradation in osteoarthritis. Osteoarthritis and Cartilage 19 874-885. (doi:10.1016/j.joca.2011. 04.014)

Clevers H 2013 The intestinal crypt, a prototype stem cell compartment. Cell 154 274-284. (doi:10.1016/j.cell.2013.07.004)

Cui Y, Niziolek PJ, MacDonald BT, Zylstra CR, Alenina N, Robinson DR, Zhong Z, Matthes S, Jacobsen CM, Conlon RA et al. 2011 Lrp5 functions in bone to regulate bone mass. Nature Medicine 17 684-691. (doi:10.1038/nm.2388)

Dallas SL, Prideaux M \& Bonewald LF 2013 The osteocyte: an endocrine cell ... and more. Endocrine Reviews 34 658-690. (doi:10.1210/er.2012-1026)

D’Amelio P, Panico A, Spertino E \& Isaia GC 2012 Energy metabolism and the skeleton: reciprocal interplay. World Journal of Orthopedics 3 190-198. (doi:10.5312/wjo.v3.i11.190)

Del Fattore A, Capannolo M \& Rucci N 2010 Bone and bone marrow: the same organ. Archives of Biochemistry and Biophysics $\mathbf{5 0 3} 28-34$. (doi:10.1016/j.abb.2010.07.020)

De-Miguel FF \& Trueta C 2005 Synaptic and extrasynaptic secretion of serotonin. Cellular and Molecular Neurobiology 25 297-312. (doi:10.1007/s10571-005-3061-z)

van Dinther M, Zhang J, Weidauer SE, Boschert V, Muth EM, Knappik A, de Gorter DJ, van Kasteren PB, Frisch C, Mueller TD et al. 2013 Antisclerostin antibody inhibits internalization of sclerostin and sclerostinmediated antagonism of Wnt/LRP6 signaling. PLOS ONE 8 e62295. (doi:10.1371/journal.pone.0062295)

Dominici M, Le Blanc K, Mueller I, Slaper-Cortenbach I, Marini F, Krause D, Deans R, Keating A, Prockop D \& Horwitz E 2006 Minimal criteria for defining multipotent mesenchymal stromal cells. The International Society for Cellular Therapy position statement. Cytotherapy 8 315-317. (doi:10.1080/14653240600855905)

Driessler F \& Baldock PA 2010 Hypothalamic regulation of bone. Journal of Molecular Endocrinology 45 175-181. (doi:10.1677/JME-10-0015)

Ducy P \& Karsenty G 2010 The two faces of serotonin in bone biology. Journal of Cell Biology 191 7-13. (doi:10.1083/jcb.201006123)

Elefteriou F 2005 Neuronal signaling and the regulation of bone remodeling. Cellular and Molecular Life Sciences 62 2339-2349. (doi:10. 1007/s00018-005-5175-3)

Elefteriou F 2008 Regulation of bone remodeling by the central and peripheral nervous system. Archives of Biochemistry and Biophysics $\mathbf{4 7 3}$ 231-236. (doi:10.1016/j.abb.2008.03.016)

Elefteriou F, Ahn JD, Takeda S, Starbuck M, Yang X, Liu X, Kondo H, Richards WG, Bannon TW, Noda M et al. 2005 Leptin regulation of bone resorption by the sympathetic nervous system and CART. Nature 434 514-520. (doi:10.1038/nature03398)
Feisst V, Brooks AE, Chen CJ \& Dunbar PR 2014 Characterization of mesenchymal progenitor cell populations directly derived from human dermis. Stem Cells and Development 23 631-642. (doi:10.1089/ scd.2013.0207)

Frost HM 1969 Tetracycline-based histological analysis of bone remodeling. Calcified Tissue Research 3 211-237. (doi:10.1007/BF02058664)

Fu S, Mei G, Wang Z, Zou ZL, Liu S, Pei GX, Bi L \& Jin D 2014 Neuropeptide substance $P$ improves osteoblastic and angiogenic differentiation capacity of bone marrow stem cells in vitro. BioMed Research International 2014 596023. (doi:10.1155/2014/596023)

Genetos DC, Yellowley CE \& Loots GG 2011 Prostaglandin E2 signals through PTGER2 to regulate sclerostin expression. PLOS ONE 6 0017772. (doi:10.1371/journal.pone.0017772)

Gifre L, Ruiz-Gaspa S, Monegal A, Nomdedeu B, Filella X, Guanabens N \& Peris P 2013 Effect of glucocorticoid treatment on Wnt signalling antagonists (sclerostin and Dkk-1) and their relationship with bone turnover. Bone 57 272-276. (doi:10.1016/j.bone.2013.08.016)

Goodrich JT, Bernd P, Sherman D \& Gershon MD 1980 Phylogeny of enteric serotonergic neurons. Journal of Comparative Neurology 190 15-28. (doi:10.1002/cne.901900103)

Guanabens N, Gifre L \& Peris P 2014 The role of Wnt signaling and sclerostin in the pathogenesis of glucocorticoid-induced osteoporosis. Current Osteoporosis Reports 12 90-97. (doi:10.1007/s11914-014-0197-0)

Gustafsson BI, Thommesen L, Stunes AK, Tommeras K, Westbroek I, Waldum HL, Slordahl K, Tamburstuen MV, Reseland JE \& Syversen U 2006 Serotonin and fluoxetine modulate bone cell function in vitro. Journal of Cellular Biochemistry 98 139-151. (doi:10.1002/jcb.20734)

Harada S \& Rodan GA 2003 Control of osteoblast function and regulation of bone mass. Nature $\mathbf{4 2 3}$ 349-355. (doi:10.1038/nature01660)

Heino TJ, Hentunen TA \& Vaananen HK 2002 Osteocytes inhibit osteoclastic bone resorption through transforming growth factor- $\beta$ : enhancement by estrogen. Journal of Cellular Biochemistry 85 185-197. (doi:10.1002/jcb.10109)

Heino TJ, Kurata K, Higaki H \& Vaananen HK 2009 Evidence for the role of osteocytes in the initiation of targeted remodeling. Technology and Health Care 17 49-56. (doi:10.3233/THC-2009-0534)

Hens JR, Wilson KM, Dann P, Chen X, Horowitz MC \& Wysolmerski JJ 2005 TOPGAL mice show that the canonical Wnt signaling pathway is active during bone development and growth and is activated by mechanical loading in vitro. Journal of Bone and Mineral Research 20 1103-1113. (doi:10.1359/JBMR.050210)

Hirvonen MJ, Fagerlund K, Lakkakorpi P, Vaananen HK \& Mulari MT 2013 Novel perspectives on the transcytotic route in osteoclasts. BoneKEy Reports 2 1-8. (doi:10.1038/bonekey.2013.40)

Johnson ML 2015 Unlocking the sost gene. Journal of Bone and Mineral Research 30 397-399. (doi:10.1002/jbmr.2459)

Khosla S, Oursler MJ \& Monroe DG 2012 Estrogen and the skeleton. Trends in Endocrinology and Metabolism 23 576-581. (doi:10.1016/j.tem.2012.03.008)

Kim CA, Honjo R, Bertola D, Albano L, Oliveira L, Jales S, Siqueira J, Castilho A, Balemans W, Piters E et al. 2008 A known SOST gene mutation causes sclerosteosis in a familial and an isolated case from Brazilian origin. Genetic Testing 12 475-479. (doi:10.1089/gte.2008.0036)

Kode A, Mosialou I, Silva BC, Rached MT, Zhou B, Wang J, Townes TM, Hen R, DePinho RA, Guo XE et al. 2012 FOXO1 orchestrates the bone-suppressing function of gut-derived serotonin. Journal of Clinical Investigation 122 3490-3503. (doi:10.1172/JCI64906)

Kogianni G \& Noble BS 2007 The biology of osteocytes. Current Osteoporosis Reports 5 81-86. (doi:10.1007/s11914-007-0007-z)

Komoroski M, Azad N \& Camacho P 2014 Disorders of bone and bone mineral metabolism. Handbook of Clinical Neurology 120 865-887. (doi:10.1016/B978-0-7020-4087-0.00058-9)

Kubota T, Michigami T \& Ozono K 2010 Wnt signaling in bone. Clinical Pediatric Endocrinology 19 49-56. (doi:10.1297/cpe.19.49)

Kular J, Tickner J, Chim SM \& Xu J 2012 An overview of the regulation of bone remodelling at the cellular level. Clinical Biochemistry 45 863-873. (doi:10.1016/j.clinbiochem.2012.03.021) 
Laine CM, Joeng KS, Campeau PM, Kiviranta R, Tarkkonen K, Grover M, Lu JT, Pekkinen M, Wessman M, Heino TJ et al. 2013 WNT1 mutations in early-onset osteoporosis and osteogenesis imperfecta. New England Journal of Medicine 368 1809-1816. (doi:10.1056/NEJMoa1215458)

Lara-Castillo N, Kim-Weroha NA, Kamel MA, Javaheri B, Ellies DL, Krumlauf RE, Thiagarajan G \& Johnson ML 2015 In vivo mechanical loading rapidly activates $\beta$-catenin signaling in osteocytes through a prostaglandin mediated mechanism. Bone 76 58-66. (doi:10.1016/ j.bone.2015.03.019)

Lau AN \& Adachi JD 2010 Role of teriparatide in treatment of glucocorticoid-induced osteoporosis. Therapeutics and Clinical Risk Management 6 497-503. (doi:10.2147/TCRM.S7776)

Leder BZ, Tsai JN, Uihlein AV, Wallace PM, Lee H, Neer RM \& Burnett-Bowie SM 2015 Denosumab and teriparatide transitions in postmenopausal osteoporosis (the DATA-Switch study): extension of a randomised controlled trial. Lancet [in press]. (doi:10.1016/S01406736(15)61120-5)

Leucht P \& Helms JA 2015 Wnt signaling: an emerging target for bone regeneration. Journal of the American Academy of Orthopaedic Surgeons 23 67-68. (doi:10.5435/JAAOS-23-01-67)

Leucht P, Jiang J, Cheng D, Liu B, Dhamdhere G, Fang MY, Monica SD, Urena JJ, Cole W, Smith LR et al. 2013 Wnt3a reestablishes osteogenic capacity to bone grafts from aged animals. Journal of Bone and Joint Surgery. American Volume 95 1278-1288. (doi:10.2106/JBJS.L.01502)

Li X, Zhang Y, Kang H, Liu W, Liu P, Zhang J, Harris SE \& Wu D 2005 Sclerostin binds to LRP5/6 and antagonizes canonical Wnt signaling. Journal of Biological Chemistry 280 19883-19887. (doi:10.1074/ jbc.M413274200)

Li X, Grisanti M, Fan W, Asuncion FJ, Tan HL, Dwyer D, Han CY, Yu L, Lee J, Lee E et al. 2011 Dickkopf-1 regulates bone formation in young growing rodents and upon traumatic injury. Journal of Bone and Mineral Research 26 2610-2621. (doi:10.1002/jbmr.472)

Li L, Yang Z, Zhang H, Chen W, Chen M \& Zhu Z 2012 Low-intensity pulsed ultrasound regulates proliferation and differentiation of osteoblasts through osteocytes. Biochemical and Biophysical Research Communications 418 296-300. (doi:10.1016/j.bbrc.2012.01.014)

van Lierop AH, Hamdy NA, van Egmond ME, Bakker E, Dikkers FG \& Papapoulos SE 2013 Van Buchem disease: clinical, biochemical, and densitometric features of patients and disease carriers. Journal of Bone and Mineral Research 28 848-854. (doi:10.1002/jbmr.1794)

Lin C, Jiang X, Dai Z, Guo X, Weng T, Wang J, Li Y, Feng G, Gao X \& He L 2009 Sclerostin mediates bone response to mechanical unloading through antagonizing Wnt/B-catenin signaling. Journal of Bone and Mineral Research 24 1651-1661. (doi:10.1359/jbmr.090411)

Logan CY \& Nusse R 2004 The Wnt signaling pathway in development and disease. Annual Review of Cell and Developmental Biology 20 781-810. (doi:10.1146/annurev.cellbio.20.010403.113126)

Loots GG, Kneissel M, Keller H, Baptist M, Chang J, Collette NM, Ovcharenko D, Plajzer-Frick I \& Rubin EM 2005 Genomic deletion of a long-range bone enhancer misregulates sclerostin in Van Buchem disease. Genome Research 15 928-935. (doi:10.1101/gr.3437105)

Loveridge N, Fletcher S, Power J, Caballero-Alias AM, Das-Gupta V, Rushton N, Parker M, Reeve J \& Pitsillides AA 2002 Patterns of osteocytic endothelial nitric oxide synthase expression in the femoral neck cortex: differences between cases of intracapsular hip fracture and controls. Bone 30 866-871. (doi:10.1016/S8756-3282(02)00732-9)

Ma W, Zhang X, Shi S \& Zhang Y 2013 Neuropeptides stimulate human osteoblast activity and promote gap junctional intercellular communication. Neuropeptides 47 179-186. (doi:10.1016/j.npep.2012.12.002)

Masi L 2012 Crosstalk between the brain and bone. Clinical Cases in Mineral and Bone Metabolism 9 13-16.

McClung MR, Grauer A, Boonen S, Bolognese MA, Brown JP, Diez-Perez A, Langdahl BL, Reginster JY, Zanchetta JR, Wasserman SM et al. 2014 Romosozumab in postmenopausal women with low bone mineral density. New England Journal of Medicine 370 412-420. (doi:10.1056/ NEJMoa1305224)
McColm J, Hu L, Womack T, Tang CC \& Chiang AY 2014 Single- and multiple-dose randomized studies of blosozumab, a monoclonal antibody against sclerostin, in healthy postmenopausal women. Journal of Bone and Mineral Research 29 935-943. (doi:10.1002/ jbmr.2092)

McNulty MS, Bedell VM, Greenwood TM, Craig TA, Ekker SC \& Kumar R 2012 Expression of sclerostin in the developing zebrafish (Danio rerio) brain and skeleton. Gene Expression Patterns 12 228-235. (doi:10.1016/j.gep.2012.04.003)

Mei G, Zou Z, Fu S, Xia L, Zhou J, Zhang Y, Tuo Y, Wang Z \& Jin D 2014 Substance $P$ activates the Wnt signal transduction pathway and enhances the differentiation of mouse preosteoblastic MC3T3-E1 cells. International Journal of Molecular Sciences 15 6224-6240. (doi:10.3390/ ijms15046224)

Mellibovsky L, Marinoso ML, Cervantes F, Besses C, Nacher M, Nogues X, Florensa L, Munne A, Diez-Perez A \& Serrano S 2004 Relationship among densitometry, bone histomorphometry, and histologic stage in idiopathic myelofibrosis. Bone 34 330-335. (doi:10.1016/j.bone. 2003.10.010)

Minear S, Leucht P, Jiang J, Liu B, Zeng A, Fuerer C, Nusse R \& Helms JA $2010 \mathrm{Wnt}$ proteins promote bone regeneration. Science Translational Medicine 2 29ra30. (doi:10.1126/scitranslmed.3000231)

Morse A, McDonald MM, Kelly NH, Melville KM, Schindeler A, Kramer I, Kneissel M, van der Meulen MC \& Little DG 2014 Mechanical load increases in bone formation via a sclerostin-independent pathway. Journal of Bone and Mineral Research 29 2456-2467. (doi:10.1002/ jbmr.2278)

Moverare-Skrtic S, Henning P, Liu X, Nagano K, Saito H, Borjesson AE, Sjogren K, Windahl SH, Farman H, Kindlund B et al. 2014 Osteoblastderived WNT16 represses osteoclastogenesis and prevents cortical bone fragility fractures. Nature Medicine 20 1279-1288. (doi:10.1038/ nm.3654)

Nakashima T, Hayashi M, Fukunaga T, Kurata K, Oh-Hora M, Feng JQ, Bonewald LF, Kodama T, Wutz A, Wagner EF et al. 2011 Evidence for osteocyte regulation of bone homeostasis through RANKL expression. Nature Medicine 17 1231-1234. (doi:10.1038/nm.2452)

Neve A, Corrado A \& Cantatore FP 2012 Osteocytes: central conductors of bone biology in normal and pathological conditions. Acta Physiologica 204 317-330. (doi:10.1111/j.1748-1716.2011.02385.x)

Ott S 2004 Bone remodelling, dynamics of. In Encyclopedia of Endocrine Diseases, vol 1.

Papanicolaou SE, Phipps RJ, Fyhrie DP \& Genetos DC 2009 Modulation of sclerostin expression by mechanical loading and bone morphogenetic proteins in osteogenic cells. Biorheology 46 389-399. (doi:10.3233/BIR2009-0550)

Parra-Torres A, Valdés-Flores M, Orozco L \& Velázquez-Cruz R 2013 Molecular aspects of bone remodeling. In Topics in Osteoporosis. Ed M Valdés-Flores. Rijeka, Croatia: InTech. (doi:10.5772/54905)

Pfeilschifter J, Seyedin SM \& Mundy GR 1988 Transforming growth factor $\beta$ inhibits bone resorption in fetal rat long bone cultures. Journal of Clinical Investigation 82 680-685. (doi:10.1172/JCI113647)

Pinkerton JV, Thomas S \& Dalkin AC 2013 Osteoporosis treatment and prevention for postmenopausal women: current and future therapeutic options. Clinical Obstetrics and Gynecology 56 711-721. (doi:10.1097/ GRF.0b013e3182a9fb02)

Pogoda P, Priemel M, Rueger JM \& Amling M 2005 Bone remodeling: new aspects of a key process that controls skeletal maintenance and repair. Osteoporosis International 16 16. (doi:10.1007/s00198-004-1787-y)

Poole KE, van Bezooijen RL, Loveridge N, Hamersma H, Papapoulos SE, Lowik CW \& Reeve J 2005 Sclerostin is a delayed secreted product of osteocytes that inhibits bone formation. FASEB Journal 19 1842-1844. (doi:10.1096/fj.05-4221fje)

Rhee Y, Lee EY, Lezcano V, Ronda AC, Condon KW, Allen MR, Plotkin LI \& Bellido T 2013 Resorption controls bone anabolism driven by parathyroid hormone (PTH) receptor signaling in osteocytes. Journal of Biological Chemistry 288 29809-29820. (doi:10.1074/jbc.M113.485938)

Published by Bioscientifica Ltd. 
Robinson JA, Chatterjee-Kishore M, Yaworsky PJ, Cullen DM, Zhao W, Li C, Kharode Y, Sauter L, Babij P, Brown EL et al. 2006 Wnt/ $\beta$-catenin signaling is a normal physiological response to mechanical loading in bone. Journal of Biological Chemistry 281 31720-31728. (doi:10.1074/ jbc.M602308200)

Roudier M, Li X, Niu QT, Pacheco E, Pretorius JK, Graham K, Yoon BR, Gong J, Warmington K, Ke HZ et al. 2013 Sclerostin is expressed in articular cartilage but loss or inhibition does not affect cartilage remodeling during aging or following mechanical injury. Arthritis and Rheumatism 65 721-731. (doi:10.1002/art.37802)

Sanchez-Fernandez MA, Gallois A, Riedl T, Jurdic P \& Hoflack B 2008 Osteoclasts control osteoblast chemotaxis via PDGF-BB/PDGF receptor $\beta$ signaling. PLoS ONE 3 e3537. (doi:10.1371/journal.pone. 0003537)

Schaffler MB, Cheung WY, Majeska R \& Kennedy O 2014 Osteocytes: master orchestrators of bone. Calcified Tissue International 94 5-24. (doi:10.1007/s00223-013-9790-y)

Sharma M, Johnson M, Brocardo M, Jamieson C \& Henderson BR 2014 Wnt signaling proteins associate with the nuclear pore complex: implications for cancer. Advances in Experimental Medicine and Biology 773 353-372. (doi:10.1007/978-1-4899-8032-8_16)

Teitelbaum SL \& Ross FP 2003 Genetic regulation of osteoclast development and function. Nature Reviews. Genetics 4 638-649. (doi:10.1038/ nrg1122)

Thiele S, Ziegler N, Tsourdi E, De Bosscher K, Tuckermann JP, Hofbauer LC \& Rauner M 2012 Selective glucocorticoid receptor modulation maintains bone mineral density in mice. Journal of Bone and Mineral Research 27 2242-2250. (doi:10.1002/jbmr.1688)

Torreggiani E, Matthews BG, Pejda S, Matic I, Horowitz MC, Grcevic D \& Kalajzic I 2013 Preosteocytes/osteocytes have the potential to dedifferentiate becoming a source of osteoblasts. PLOS ONE 8 e75204. (doi:10.1371/journal.pone.0075204)

Tu X, Joeng KS, Nakayama KI, Nakayama K, Rajagopal J, Carroll TJ, McMahon AP \& Long F 2007 Noncanonical Wnt signaling through G protein-linked PKC $\delta$ activation promotes bone formation. Developmental Cell 12 113-127. (doi:10.1016/j.devcel.2006.11.003)

Tu X, Rhee Y, Condon KW, Bivi N, Allen MR, Dwyer D, Stolina M, Turner CH, Robling AG, Plotkin LI et al. 2012 Sost downregulation and local Wnt signaling are required for the osteogenic response to mechanical loading. Bone 50 209-217. (doi:10.1016/j.bone.2011.10.025)

Turner CH, Robling AG, Duncan RL \& Burr DB 2002 Do bone cells behave like a neuronal network? Calcified Tissue International 70 435-442. (doi:10.1007/s00223-001-1024-z) de Vernejoul MC, Collet C \& Chabbi-Achengli Y 2012 Serotonin: good or bad for bone. BoneKEy Reports 1 1-6. (doi:10.1038/bonekey.2012.120)

Wang Y, Li YP, Paulson C, Shao JZ, Zhang X, Wu M \& Chen W 2014 Wnt and the Wnt signaling pathway in bone development and disease. Frontiers in Bioscience 19 379-407. (doi:10.2741/4214)

Wijenayaka AR, Kogawa M, Lim HP, Bonewald LF, Findlay DM \& Atkins GJ 2011 Sclerostin stimulates osteocyte support of osteoclast activity by a RANKL-dependent pathway. PLoS ONE 6 e25900. (doi:10.1371/journal. pone.0025900)

Winkler DG, Sutherland MK, Geoghegan JC, Yu C, Hayes T, Skonier JE, Shpektor D, Jonas M, Kovacevich BR, Staehling-Hampton K et al. 2003 Osteocyte control of bone formation via sclerostin, a novel BMP antagonist. EMBO Journal 22 6267-6276. (doi:10.1093/emboj/cdg599)

Xiong J, Onal M, Jilka RL, Weinstein RS, Manolagas SC \& O’Brien CA 2011 Matrix-embedded cells control osteoclast formation. Nature Medicine $\mathbf{1 7}$ 1235-1241. (doi:10.1038/nm.2448)

Yadav VK, Ryu JH, Suda N, Tanaka KF, Gingrich JA, Schutz G, Glorieux FH, Chiang CY, Zajac JD, Insogna KL et al. 2008 Lrp5 controls bone formation by inhibiting serotonin synthesis in the duodenum. Cell 135 825-837. (doi:10.1016/j.cell.2008.09.059)

Yadav VK, Oury F, Suda N, Liu ZW, Gao XB, Confavreux C, Klemenhagen KC, Tanaka KF, Gingrich JA, Guo XE et al. 2009 A serotonin-dependent mechanism explains the leptin regulation of bone mass, appetite, and energy expenditure. Cell 138 976-989. (doi:10.1016/j.cell.2009.06.051)

York SL, Sethu P \& Saunders MM 2015 Impact of gap junctional intercellular communication on MLO-Y4 sclerostin and soluble factor expression. Annals of Biomedical Engineering [in press]. (doi:10.1007/ s10439-015-1376-6)

Zhang J, Zhou B, Liu Y, Chen K, Bao P, Wang Y, Wang J, Zhou Z, Sun X \& Li Y 2014 Wnt inhibitory factor-1 functions as a tumor suppressor through modulating Wnt/ß-catenin signaling in neuroblastoma. Cancer Letters 348 12-19. (doi:10.1016/j.canlet.2014.02.011)

Zhou YJ, Li A, Song YL, Zhou H, Li Y \& Tang YS 2013 Role of sclerostin in the bone loss of postmenopausal chinese women with type 2 diabetes. Chinese Medical Sciences Journal 28 135-139. (doi:10.1016/S10019294(13)60038-3)

Zhu ED, Demay MB \& Gori F 2008 Wdr5 is essential for osteoblast differentiation. Journal of Biological Chemistry 283 7361-7367. (doi:10.1074/jbc.M703304200)

Zuo C, Huang Y, Bajis R, Sahih M, Li YP, Dai K \& Zhang X 2012 Osteoblastogenesis regulation signals in bone remodeling. Osteoporosis International 23 1653-1663. (doi:10.1007/s00198-012-1909-x)

Received in final form 17 August 2015

Accepted 24 August 2015

Accepted Preprint published online 24 August 2015 http://jme.endocrinology-journals.org

DOI: 10.1530/JME-15-0067
(C) 2015 Society for Endocrinology Printed in Great Britain
Published by Bioscientifica Ltd. 